\title{
REFLECTION
}

\section{Learning Through Vulnerability: A Mentor-Mentee Experience}

Kobar Jones, $M D^{1,3}$

Shmuel Reis, MD, MHPE $E^{2,3}$

'Department of Family Medicine, University of Chicago Medical Center, Chicago, Illinois

${ }^{2}$ Department of Family Medicine, R\&B Rappaport Faculty of Medicine, Technion-Israel Institute of Technology, Haifa, Israel

${ }^{3}$ Warren Alpert Medical School of Brown University, Providence, Rhode Island

Conflicts of interest: none reported

\section{CORRESPONDING AUTHOR}

Kohar Jones, MD

5841 S Maryland Ave

MC 7110, Suite M-146

Chicago, IL 60637-1470

kjones1@bsd.uchicago.edu

\begin{abstract}
The following essay, drawn from the journals and work notebook of a family medicine resident and a visiting clinical mentor, chronicles their work together in an Advanced Clinical Mentoring program. This program included afternoons of direct clinical observation immediately followed by feedback sessions. In addition to addressing specific professional issues, such as time management, limiting patient encounters, agenda matching, and the One-Minute Preceptor model, the authors developed personally as they opened themselves to learning and growing as a clinician and a teacher.
\end{abstract}

Ann Fam Med 2010;8:552-555. doi:10.1370/afm.1165.

$t$ the start of my third year of family medicine training, I began to
fear that I was falling off the normal resident development curve as
I struggled to fit my patients' complicated needs within an increasingly short clinic visit. I needed concrete skills to keep the visit lengths manageable. My residency director suggested I pilot a residency mentoring program with a visiting physician.

After almost 30 years of rural practice and academic work in the Technion University, in Haifa, Israel, I finally took a year-long sabbatical. Although I am used to being in control, planning, and achieving, and I came to Brown with some intentions to further my mentoring skills, write, and reflect, I bad no plan. One of the first ideas that came up in discussion with the department chair was to work with the residents. He devised a title: Advanced Clinical Mentoring. I liked the idea, yet I bad no idea bow it would unfold. Yes, this prospect was risky, and I was anxious, outside my language, away from my bome environment, preparing to step into the role of advanced clinician, whatever that meant.

We met in the morning just before your clinic. You told me what you were boping to accomplish — managing time and reenergizing your morale for the task beyond residency. I proposed shadowing, and you agreed. There was a student as well. We agreed you would tutor ber as usual, and I would comment if needed. I put on a white coat and a badge, and we jumped in.

We were 3 generations of physicians. As our entourage entered each examination room, I introduced you as "Master Doctor" Reis, helping me to become a better doctor, before introducing the "student doctor," who would take an initial history and perform a physical examination before I came back into the room to wrap up the visit, if that were all right with the patient?

The patients smiled at the progression of learning, and we moved through our afternoon schedule.

So strange, I was a fly on the wall, doing nothing but noticing. I had never been in such a situation, and for a whole afternoon. My urges to jump into the situation ebbed and flowed. I observed for a few minutes, then reached into my pocket and took out my notebook. Taking notes belped keep my anxiety in check. I was writing notes intuitively: some clinical details and the rest observations and running commentary. 
Would I make sense when it came to the actual mentoring?

The medical student described the first patient to me: "33 years old with a history of breast cysts with tenderness; she's afraid she has breast cancer."

"What's her family history?"

We returned to the room to find out.

She told us details of her pain, of her life, and revealed that, yes, her mom had breast cancer diagnosed at age 33 years, and died 10 years later. She began to cry.

"I'm so worried I have cancer too."

I comforted her, counseled her, talked of mammograms, ultrasound procedures, and genetic counseling, Then I asked her to undress for the breast examination and left the room, where nurses accosted me with forms to sign for other patients, then my pager beeped with an urgent call about a patient in drug rehab, and suddenly 15 minutes had evaporated. I didn't realize it until the patient came into the hallway wrapped in her paper gown and demanded to know what was taking so long.

I had acknowledged her fears of cancer, and then left her alone with them naked in the examining room.

I felt the 1-2 punch that was sinking me-trying to overreach, do too much for everyone, only to not do enough, to take too long. I decided to send her for the mammogram and ultrasonography without the breast examination, and continued my day.

I witnessed your moment of difficulty; part of me was sinking in tandem. You took a long moment to collect yourself - then changed course. I wrote to myself_critical incident_-good decision making.

It clicks in for me. I am not a foreigner in the land of patients, their care, and docs, nor am I a stranger to deep listening and empatby. I navigate, putting myself in the patient's shoes, your shoes, and the student's shoes. I feel joy seeing how my years of practice and reflection become bandy.

In our wrap-up discussion at the end of our first day together, I returned to this patient interaction, which demonstrates both what I love and hate about medicine.

I love figuring out that it wasn't the breast pain bothering her, but her fear of cancer and her own mortality as she reached the age when her mother received her death sentence. I love treating not just symptoms, but addressing the psychosocial environment that makes those symptoms appear in the first place.

I hate keeping people waiting while I try to provide everything for everybody, in the process frustrating my patients, my staff, and myself.

At the end of the day, you wanted insight and empowerment for action. I was reactive, transmitting practical/technical models and ideas, such as family-orientation, Medalie's levels of practice, ${ }^{1}$ agenda setting, ${ }^{2}$ and the One-Minute Preceptor. ${ }^{3}$ I was still tense but felt on track, allowing what felt right to surface and be spelled out. The day validated the skills, experience, and integrated frame- work that had been accumulating in me for decades, as well as gave me a vision of what may be coming next. I would move into my life as a grandfather personally and professionally, returning bome with the courage to try the new learning techniques.

This was my first advanced clinical mentoring (whatever it meant), and it felt fragile and precious and risky, yet strangely familiar and liberating. By being attentive and mindful, accepting risk and vulnerability, we were creating a learning opportunity for both of us.

You presented a solution. If I wanted to be able to go home at a reasonable time with no more charts to write, no lingering unreturned telephone calls, I'd need to learn how to limit my scope of practice.

I'd need to find out what they wanted from the visit and to shape the visit to meet their agenda.

You explained Jack Medalie's model of the different levels of practice, telescoping outward from symptoms to diseases, to the whole person sitting before me in my clinic, living in their unique psychosocial environment comprised of interactions with their family and community.

From symptoms to society.

If I could widen my scope of practice for just 1 clinic visit each day, and go home happy, my day complete, I would have succeeded in becoming the family physician I dreamt of becoming.

You also introduced me to the concept of the OneMinute Preceptor, asking medical students to respond to pointed clinical questions. Based on the history and physical examination, what did they think might be going on? What diagnostic steps could we take to differentiate the diagnosis? What might potential treatments be? I could quickly assess medical students' level of knowledge and teach to their learning needs.

During our wrap-up, I modeled the One-Minute Preceptor, the clinical training tool for teaching on the fly about clinical problem solving, eliciting your reasoning (as well as needs) and commenting briefly. Here we adapt it to mentoring on the fly. Is it working? It seems so. I can relax a bit now.

After our session together, I consciously limited my scope of practice to the chief complaint before me that day. When patients tried to ask for more than we could address in our allotted time, I reminded them we had 15 minutes, and asked them to choose what they wanted to deal with that day. Simple, no? I learned so much from the first session, I requested another mentoring session.

During the second session with you, 3 weeks later, 2 tattooed men, 2 beel spurs, a breast lump, and then "Mr 18 issues" (with many more in review of systems), a murderer. Your first murderer, I bad a few, but notbing like that one. You already implement the agenda setting we discussed: "What would you like me to do for you today?"

I saw an overweight woman complaining of pain 
from her heel spurs that ibuprofen wouldn't touch. She wanted stronger medications.

"You can try icing it," I suggested, "and stretching."

"That's not easy for me."

I demonstrated the stretches from my stool.

"I can't do that," she said. "Can't you give me a pill to help?"

"I prefer not to use more than you're already using. We could also try an injection," I said. She refused again, no needles, and pushed for a stronger medicine.

"Let me show you other stretches that may be easier for you," I stood up from my stool and demonstrated against the wall.

She refused again. "But what about my pain, doctor?"

I capitulated. She left with a short-term prescription for narcotics, and a referral to physical therapy.

Frustration.

She wanted controlled substances, I didn't want to give them, and we spent too long negotiating for her to end up with what she wanted anyway, with the caveat that there would be no refills without her trying physical therapy.

Ian McWbinney's patient-centered clinical method comes to mind: noticing the doctor's and patient's agendas, and evaluating their concordance. It will not work, in spite of best intentions, to make a patient do physical therapy if she has a diametrically opposite agenda. It can save a lot of energy and frustration to diagnose this mismatch. I point it out to you, and you are applying it in the next complex patient. What a joy!

And then there was Monsieur Manslaughterer.

"He's complicated," you said, my time watcher and encounter understander. "He presented 18 problems in 10 to 15 minutes."

Bipolar. Post-traumatic stress disorder. Homeless. Phoneless. Gay and unable to live with his lover because of housing regulations allowing spouses, but no roommates. Noncompliant with medications. Refusing to see a psychologist. He proudly showed off the scars on his arms that landed him in the psychiatric hospital last year for 10 days. He wanted to talk about his tooth pain. And back pain. And joint pain. And full-body, full-life pain.

Not to mention a long former bistory of sexual abuse, restless legs syndrome, eye twitching, and a 21-year-old son that still comes back bome to live.

"I'm a pain in the ass!" he said, proudly.

He comes to us for Percocet, prescribed by the doctors of this clinic. But we can't medicate away a pain in the ass, the pain of his life-of his no-good, beaten-up, man-murdering life. Five years he spent in jail.

"He abused me, I stabbed him, he died."

After he mentioned his current suicidality, I delayed his routine care and handed him off to our staff psychologist, who knew him well. "He's been here before," she sighed, after going into the room with the patient and walking him to a phone to call his case manager.

"I've done exactly this, not just once but twice before."

Impressive containment. Trust the clinic process. The system works.

Our mentoring is working too. We are moving fast from my observations to your empowered action with the next patients. You are no longer overwbelmed. Neither am I.

I am learning to trust the mentoring process. Our system works - autbentically being present, using models that fit the situation to cognitively scaffold the learning, and identifying learning opportunities that transcend and integrate the problem solving.

By inviting a senior physician to observe my clinical encounters for an entire clinic session, encompassing both smooth and difficult patient interactions, I gained confidence in myself as a clinician. By opening myself to feedback and new learning models, I learned to be a more efficient doctor for difficult patients, and a more effective clinical teacher.

Now I have tools to manage each clinic day.

"What can I do for you today?"

From McWhinney, I have learned to determine the patient agenda, acknowledge that we can't do everything in a single visit, and together we prioritize their problems.

"You're telling me a lot of problems. Let's make a list, then decide which one we will deal with today."

I match my actions to their expectations or talk them into my agenda if need be. We move forward, as a team, to answer their needs.

When they expect too much, I say:

"We have 15 minutes together today. You can come back in 2 weeks, and we'll give each problem the attention it deserves."

From Medalie, I have learned to recognize when a patients' needs are beyond a doctor-patient clinical encounter

"Let me put you in touch with my colleague."

I hand off the psychological needs to the psychologist, the social needs to the social worker, identifying the complex needs in the clinic visit but turning to other members of the health care team to respond. I remain focused on addressing and ameliorating the physical symptoms, diagnosing and treating disease in 15 minutes or less.

Applying the One-Minute Preceptor model, I have learned to elicit what medical students know and teach them what they have not yet learned.

"What do you think is going on? What do you want to do? Why?"

In very little time I acknowledge their strengths and teach to their weaknesses.

Through my mentor, I have learned from the masters. 
Learning from vulnerability is the construct that starts resonating with me-this is how I bave grown, this is how you are growing now. In this mentoring experience I have been moving away from my comfort zone, pushing my safety limits. We all get uncomfortable as we reach our safety limits; we become vulnerable. By embracing this vulnerability, growth becomes possible. When I am mindful of $m y$ fear and at the same time notice, reflect, and accept it, I may be breaking through my vulnerabilities to a position of strength. In this process, I extended what I am able to do comfortably.

We drew on direct clinical observation followed by the transmittance of clinic models from the mentor to the mentee as a springboard for clinical growth. I subseduently applied this ongoing process of learning to other residents, to senior faculty including the chair, and in other departments. Three months down the road I was shadowing a senior doc at a distant institution, and a year later I am introducing it at bome.

All clinicians at all stages of training and mentoring are lifelong learners. Advanced Clinical Mentoring provides a model for the continuing medical education of clinical skills.

To read or post commentaries in response to this article, see it online at http://www.annfammed.org/cgi/content/full/8/6/552.

Key words: Residency, medical/education; mentors; time management; medical education; clinical competence; physician-patient relations; job satisfaction

Submitted October 8, 2009; submitted, revised, March 27, 2010; accepted April 5, 2010.

\section{References}

1. Medalie J, ed. Introduction. In Family Medicine: Principles and Practice. Baltimore, MD: Williams \& Wilkins; 1978.

2. McWhinney IR, Freeman T. Textbook of Family Medicine. New York, NY: Oxford University Press; 2009.

3. Neher JO, Gordon KC, Meyer B, Stevens N. A five-step "microskills" model of clinical teaching. J Am Board Fam Pract. 1992;5(4):419-424.

Please complete this form and mail to the following address or fax to Annals Circulation at 913-906-6080:

Annals of Family Medicine, Circulation Department, 11400 Tomahawk Creek Pkwy, Leawood, KS 66211-2680

Check if member of sponsoring organization: $\square$ AAFP $\quad \square$ ABFM $\quad \square$ STFM $\square$ ADFM

$$
\square \text { AFMRD } \square \text { NAPCRG } \square \text { CFPC }
$$

ID number from label on your journal cover

OLD Information (Please print.)

$$
\text { Name }
$$

Company (if applicable)

Address (Street plus Apt or Ste)

\begin{tabular}{lc}
\hline City & State \\
\hline Country & Postal Code (9-digit ZIP for US) \\
\hline Telephone & Fax \\
\hline E-Mail &
\end{tabular}

NEW Information (Please print.)

\begin{tabular}{ll}
\hline Name \\
\hline Company (if applicable) \\
\hline Address (Street plus Apt or Ste) \\
\hline City & \\
\hline Country & Postal Code (9-digit ZIP for US) \\
\hline Telephone & Fax \\
\hline E-Mail &
\end{tabular}

